\title{
Failure to refill essential prescription medications for asthma among pediatric Medicaid beneficiaries with persistent asthma
}

This article was published in the following Dove Press journal:

Patient Preference and Adherence

8 January 2013

Number of times this article has been viewed

\author{
Varun Vaidya' \\ Renuka Gupte ${ }^{2}$ \\ Rajesh Balkrishnan ${ }^{3}$ \\ 'Pharmacy Health Care \\ Administration, Department \\ of Pharmacy Practice, University \\ of Toledo College of Pharmacy, \\ Toledo, OH, USA; '2Private Practice, \\ Sylvania, OH, USA; ${ }^{3}$ Department of \\ Clinical, Social and Administrative \\ Sciences, Pharmacy, The University of \\ Michigan, Ann Arbor, MI, USA
}

\begin{abstract}
The problem of patients not taking medications as prescribed, also known as "lack of medication adherence," is widely discussed as an issue related to suboptimal outcomes and excess health care expenditure. Although medication adherence is defined as patients not taking medications as prescribed, there are two elements to it: first, those who fail to follow the medication regimen by skipping a dose or not following the instructions, resulting in poor adherence with prescribed medicines; and, second, the patient who does not take the medication at all or stops after the initial fill. The existing literature contains a lot of studies on the first element, but very little is known about those who stop taking their medication after the initial fill or do not take it at all. In this study, our focus is on identifying patients who fail to refill a prescription for essential medicines, such as asthma-controlling drugs. Using Medicaid claims datasets, this study analyzed a pediatric population diagnosed with persistent asthma that discontinued an essential controlling medication after the initial fill. We found that more than half of this population did not continue their medication after the first fill. While there might be many reasons behind the failure to refill such medications, our data indicate that race/ethnicity, comorbid illness, and type of Medicaid plan are potentially associated with such behavior. Future research is warranted to understand this issue further and identify specific factors causing such behavior, such that strategies may be formulated by which poor adherence can be minimized.
\end{abstract}

Keywords: medication adherence, asthma, Medicaid, controller medication, prescription refill

\section{Introduction}

Nonadherence leads to morbidity, mortality in chronic disease, and preventable health care costs. ${ }^{1-5}$ Often referred to as noncompliance with medication, nonadherence with medication is defined as the extent to which a patient's behavior conflicts with a physician's recommendation. ${ }^{1}$ Nearly three in four Americans fail to follow their doctor's instructions for taking prescription drugs, a problem that is associated with 125,000 patient deaths each year, according to the National Consumers League. ${ }^{6}$ Although the effectiveness and benefits of prescription drugs are well known and extensively researched, proper use of medication remains a problem for both patients and providers. ${ }^{1}$ While some underuse is the result of underdiagnosis or undertreatment, a good deal is due to patients simply not taking their prescribed medications. ${ }^{7}$

While nonadherence with medication is broadly defined as taking less medication than prescribed, most of the research using prescription claims data has focused on determining optimum adherence rates and characterizing patients as adherent based on cutoff points such as $70 \%-80 \%$ refill rate. ${ }^{8}$ This research has helped to explain many aspects of lack of optimum adherence; however, very little is known about patients who
Correspondence: Varun Vaidya

Pharmacy Health Care Administration, Department of Pharmacy Practice, University of Toledo College of Pharmacy, Health Science Campus 3000 Arlington Ave, Toledo, $\mathrm{OH} 436 \mathrm{I} 4$, USA

$\mathrm{Tel}+\mathrm{I} 4193831516$

Email varun.vaidya@utoledo.edu 
never fill their prescriptions or who stop taking medications after the first fill. A 2003 World Health Organization report on long-term adherence showed that many patients discontinued their medications after first fill. ${ }^{9}$ Being diagnosed with a chronic condition is likely to motivate such patients to get the initial prescription, but over time, it is also likely to weaken the perceived need and motivation, resulting in failure to continue the prescribed regimen.

In this study, our goal was to identify newly diagnosed patients with asthma who stopped taking medications after their first fill and to identify characteristics associated with this behavior. Asthma affects all age groups, and its influence on the daily lives of patients and their families is enormous. Asthma is a significant public health problem associated with larger functional consequences. ${ }^{10}$ The existing literature on asthma points towards significant underuse of asthma medications, particularly the preventive or controller medications, such as inhaled corticosteroids. ${ }^{11,12}$ Despite the treatment guidelines on the importance of using controller medication, underuse is very prevalent. ${ }^{11}$ In our analysis, we focused on newly diagnosed pediatric patients with asthma who abruptly discontinued taking their medication after the initial fill. The study population we chose was pediatric asthma patients (age $<16$ years) who rely on Medicaid for their health care needs. Because Medicaid is a health program that covers families with low incomes and resources, we hypothesized that these beneficiaries would be very vulnerable to failure to continue medications after initial fill.

\section{Materials and methods}

The present study used a retrospective cohort design involving Medicaid data licensed from Thomson Medstat. The data were from multiple states representing each geographical region of the United States. The study population was assembled from Centers for Medicare and Medicaid Services data for 2006-2007. The database incorporates pooled health care utilization data for more than 7 million Medicaid enrollees from 1999. It consists of both outpatient and inpatient medical services. Long-term care claims, medication, and eligibility information for the enrollees are also included in the database. ${ }^{7}$ This dataset is frequently used to conduct research on adherence to medication literature..$^{13,14}$

\section{Study population}

Based on the outpatient claims from January 2006 to December 2007, asthma patients aged $<16$ years were identified by the presence of an ICD-9-CM code 493.XX in the primary or secondary diagnosis field. Based on analysis of prescription drug records, those on controller therapy between June 2006 and June 2007 were identified by the presence of at least one claim for inhaled corticosteroids, cromolyn, or montelukast. The date on which the first occurrence of a controller medication claim was made was recorded as the index date, and controller drug utilization for 6 months before and after the index date was studied. Patients having no evidence of any controller medication in the 6 months prior to the index date were included in the study (Figure 1). Study participants that were dual-eligible (eligible for both Medicare and Medicaid) were excluded from the analysis.

\section{Measurement and outcomes}

The primary outcome of interest in this study was discontinuation of controller medication prescribed after the initial fill. The prescription claims database contained brand and dose information on all prescriptions filled and pharmaceutical claims data. Based on this information, patients were categorized into those who failed to continue the prescription and those who continued their medications after first refill. The data were analyzed using SAS software version 9.2 (SAS Institute, Cary, NC). Descriptive statistics were computed to compare baseline patient characteristics. While continuous data were described by the mean \pm standard deviation, nominal values were expressed as percentages. Multivariate modeling was performed to determine the predictive ability of potential explanatory variables for the odds of an asthma patient exhibiting nonadherent attributes.

Selection of potentially predictive variables was based on Andersen's behavioral model of health services use. ${ }^{15-18}$

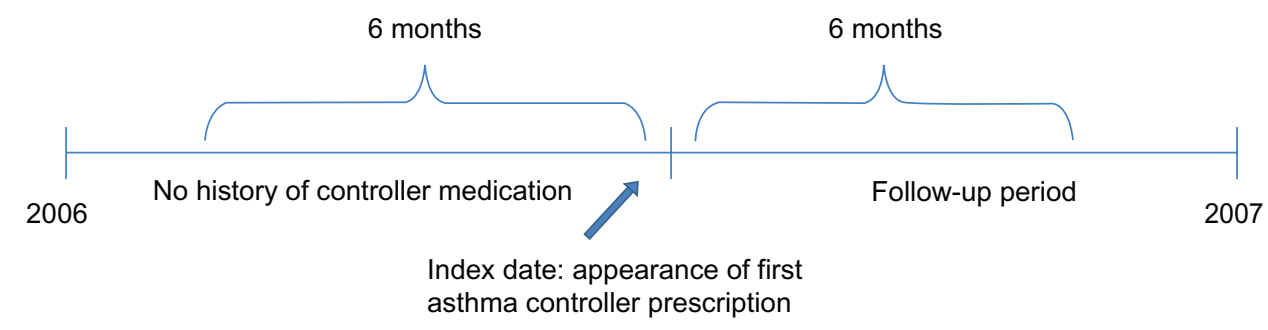

Figure I Patient identification. 
There were more than 7 million patients in the Thomson Medstat MarketScan 8 State Medicaid database during the study period

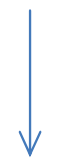

Of these patients, a total of 419,310 were found have a diagnosis for asthma

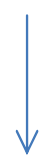

Further patients were screened to find 34,134 newly initiated on ICS (no history of ICS prior to index date)

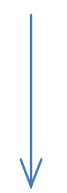

Of these cases 14,671 were continually enrolled in Medicaid for the entire study period

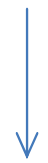

Patients that were found to be eligible for Medicare were excluded, leaving a total of 12,974 patients

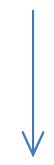

Finally, applying the age criterion (age $<6$ years), the final sample included a cohort of 8892 patients

Figure 2 Sample selection criteria details. Abbreviation: ICS, inhaled corticosteroids.

This model captures health services utilization behavior as a function of their predisposition to use, enabling resources to use, and need to use the health services. This model is widely accepted in the literature on health care utilization research. ${ }^{13,14}$ Use of this model helped to identify variables that may influence utilization behavior. The covariates capturing predisposing, enabling, and need factors include age, sex, race/ethnicity, capitation/fee-for-service, and comorbidity score. The Charlson Comorbidity Index was used to assign a value for pre-existing comorbid conditions. This value is based on 19 comorbid conditions, each of which has a correlated prognostic weight ranging from 1 to 6 . A mean Charlson comorbidity score of 1.8 with a standard deviation of 1.4 was calculated from our study population. This index is a widely used validated method for estimating risk of death due to various comorbid conditions. It has also been validated for several other health outcomes besides death. Age was excluded from the computation of our comorbidity score.

\section{Results}

The dataset had a total of 7.4 million individuals. Of these, 419,310 were found to be diagnosed with asthma. After applying the inclusion/exclusion criteria, there were 8892 patients who met the requirements for this study (Figure 2). Of these patients, $3668(41.25 \%)$ were male and $5224(58.75 \%)$ were female. The study cohort comprised white $(\mathrm{n}=3648$, $41.03 \%)$, black $(n=3393,38.16 \%)$, and Hispanic $(n=242$, $2.72 \%$ ) subjects. The mean age of our study subjects was 7.02 years of age with a standard deviation of 3.87 years (Table 1). Of the total 8892 patients, 5046 (56\%) patients stopped filling their prescriptions after the initial fill.

The bivariate analysis between various characteristics and the dependent variable showed that 5046 patients did not refill their prescription after the initial fill, accounting for $56.75 \%$ of the total population. In all demographic categories, such as race, ethnicity, and sex, the percentage of those who discontinued after the initial prescription was significantly higher. Also, regardless of type of plan, higher percentages 
Table I Patient characteristics for the study population $(n=8892)$

\begin{tabular}{lll}
\hline Variable & $\mathbf{n}$ (mean) & \% (SD) \\
\hline Age, years & 7.02 & 3.87 \\
Sex & & \\
Male & 3668 & 41.25 \\
Female & 5224 & 58.75 \\
Race & & \\
White & 3648 & 41.03 \\
Black & 3393 & 38.16 \\
Hispanic & 242 & 2.72 \\
Other & 1609 & 18.09 \\
Plan type & & \\
FFS & 2948 & 33.15 \\
Non-FFS & 5944 & 66.85 \\
CCl & 1.8 & 1.4 \\
Total & 8892 & 100.00 \\
\hline Abbreviations & CCI, Chrson Comb
\end{tabular}

Abbreviations: $\mathrm{CCl}$, Charlson Comorbidity Index; FFS, fees for service; SD, standard deviation.

were noted for those who failed to refill. Table 2 summarizes all the raw numbers and percentages.

A multiple logistic regression model analyzed the relationship between various covariates and the dependent variable, which was failure to refill the initial prescription. Table 3 summarizes the results of this analysis by presenting the odds of failure to refill for various characteristics. The odds ratio for black patients was 0.893 with a $95 \%$ confidence interval (CI) of $0.809-0.986$. Thus, for a white patient, the odds of failure to refill were 1.12 times larger than the odds for a black patient. The results for Hispanic subjects and subjects categorized as "other" were similar, with an odds ratio of 0.85 (95\% CI $0.652-1.108)$ and an odds ratio of 0.842 (95\% CI 0.742-0.954), respectively. The comorbidity score was also statistically significant, with an odds ratio of 0.801 (95\% CI 0.73-0.879). In addition, fees-for-service plans

Table 2 Total number and percentage of patients who continued after initial fill and those who did not

\begin{tabular}{llll}
\hline & Failure to refill, $\mathbf{n}$ & Continued, n & P-value \\
\hline Sex & & & \\
Male & $2051(55.92 \%)$ & $1617(44.08 \%)$ & 0.001 \\
Female & $2995(57.33 \%)$ & $2229(42.67 \%)$ & \\
Race & & & \\
White & $1991(54.58 \%)$ & $1657(45.42 \%)$ & $<0.005$ \\
Black & $1949(57.44 \%)$ & $1444(42.56 \%)$ & \\
Hispanic & $141(58.26 \%)$ & $101(41.74 \%)$ & \\
Other & $965(59.98 \%)$ & $644(40.02 \%)$ & \\
Plan type & & & \\
FFS & $1589(53.90 \%)$ & $1359(46.10 \%)$ & $<0.005$ \\
Non-FFS & $3457(58.16 \%)$ & $2487(41.84 \%)$ & \\
Total & $5046(56.75 \%)$ & $3846(43.25 \%)$ & \\
\hline
\end{tabular}

Abbreviation: FFS, fees for service.
Table 3 Factors associated with failure to refill the prescription: logistic regression analysis

\begin{tabular}{|c|c|c|c|}
\hline \multirow{2}{*}{$\begin{array}{l}\text { Variable } \\
\text { Race }\end{array}$} & \multirow[t]{2}{*}{ Odds ratio } & \multicolumn{2}{|c|}{$\begin{array}{l}95 \% \text { confidence } \\
\text { interval }\end{array}$} \\
\hline & & & \\
\hline White & (Reference) & & \\
\hline Black & 0.893 & 0.809 & 0.986 \\
\hline Other & 0.842 & 0.742 & 0.954 \\
\hline Hispanic & 0.85 & 0.652 & 1.108 \\
\hline \multicolumn{4}{|l|}{ Sex } \\
\hline Male & 0.939 & 0.862 & 1.023 \\
\hline Female & (Reference) & & \\
\hline Comorbidity score & 0.801 & 0.730 & 0.879 \\
\hline Age & 1.014 & 0.966 & 1.064 \\
\hline Age square & 0.999 & 0.996 & 1.002 \\
\hline \multicolumn{4}{|l|}{ Type of plan } \\
\hline FFS & 1.18 & 1.072 & 1.298 \\
\hline Non-FFS & (Reference) & & \\
\hline
\end{tabular}

Abbreviation: FFS, fees for service.

(odds ratio $1.18,95 \%$ CI 1.07-1.29) were also predictive of failure to refill.

\section{Discussion}

Adherence to chronic care medication is a significant problem in the US health care system. The cost burden of nonadherence is estimated to be $\$ 100$ billion. ${ }^{19}$ A significant body of research exists to underline the suboptimal efficacy and financial burden resulting from adherence-related issues. ${ }^{20}$ In this study, we focused on a population that discontinues drug use immediately after they are prescribed the regimen, an area that is much less explored. In the study population, we found a significant proportion of patients quitting use of medication soon after the initial prescription. For a condition like persistent asthma, controller medications are extremely useful in avoiding unnecessary worsening of the condition and the resulting cost burden. ${ }^{21}$ Even though controller medications do not have any symptomatic relief associated with their use, they are very important in controlling the underlying inflammation which causes exacerbations and worsening of the disease. If such inflammation remains unchecked, it develops into a much more severe form that drives higher costs and reduces quality of life for patients. ${ }^{22}$ In light of these facts, a noncompliance rate of $56 \%$ among our study population is alarming. Also, the population consisted of children who rely on a safety net for their health care needs. Prior research has shown the vulnerability of this population to comparatively poor health outcomes. One of the potential reasons behind overall poor health could be the very low or absent use of essential prescription medications. Again, we would like to emphasize the fact that this rate does not 
represent a population that has merely low adherence. This rate shows almost no use of asthma controller medications, although patients are actually in need of it. Further, we studied any possible predicting factors contributing to early discontinuations using the variables available in the datasets.

In the analysis to find predictors influencing failure to refill, we found a significant association with race/ethnicity, comorbid conditions, and plan type. In terms of race and ethnicity, we found a higher likelihood among the majority population (whites) compared with minorities of not refilling their prescribed regimens. This is contradictory to the existing research showing lower adherence levels among black patients. It is possible that whites who continue to fill their medications beyond the initial prescription tend to be more disciplined in terms of filling subsequent prescriptions compared with minorities, even though a higher percentage of them belong to the category that does not refill after initial prescription.

It should also be noted that, in some cases, discontinuation of controller medication could have been initiated by prescribers and not by patients in situations such as the medication being observed to have no effects or being prescribed temporarily for seasonal purposes. Therefore, the overall failure rate presented may have been slightly overestimated.

More research is warranted to explore this association and its implications further. Interestingly, the comorbidity score was also found to have an inverse relationship with failure to refill prescription, which may be due to the lack of seriousness towards the treatment because of relatively better overall health characterized by absence of other major comorbidities. This is consistent with the existing literature. ${ }^{23}$ In an era of rising health care costs and increasingly complex health care, it is very important to address every single issue that would help to reduce the cost burden by avoiding unnecessary spending. In the case of asthma, emergency room visits and hospitalizations drive all the major costs, ${ }^{24}$ so it is extremely important to address issues such as improving appropriate utilization of essential drugs that are considerably less costly to restore or improve quality of life.

Although we tried to adjust for biases associated with the observational data, there were some limitations that are inherent in study designs which are not experimental. The patients included in this study were newly diagnosed with asthma and had a history of at least one prescription fill. This approach might not capture another subsection of the asthma population that never filled a prescription for asthma controller drugs or never filed a claim through
Medicaid. Due to the lack of data on prescription records, such as the electronic medical record, we had to rely on administrative claims. Therefore, it should be noted that the results presented here for the proportion of nonusers may be an underestimation of a problem which may be even more alarming. A study using extensive electronic medical record data can reveal such populations as well. Another limitation was that although the dataset for this study came from four states, we could not adjust it for state variations due to lack of a state identifier.

\section{Conclusion}

The issue of underutilization of essential prescription drugs is putting a burden on health care and the cost of health care. What is even more worrisome is the lack of use of essential medications. In this study, we found that a significant proportion of pediatric Medicaid patients discontinued their regimen immediately after the first fill. More research and policy changes are warranted to examine and address the problem of patients foregoing their medications.

\section{Acknowledgment}

The authors would like to acknowledge Jacquelyn Lehman for help with the organization of this paper.

\section{Disclosure}

The authors report no conflicts of interest in this work.

\section{References}

1. Osterberg L, Blaschke T. Adherence to medication. $N$ Engl J Med. 2005;353:487-497.

2. Lau PM, Stewart K, Dooley MJ. Comment: hospital admissions resulting from preventable adverse drug reactions. Ann Pharmacother. 2003;37:303-304.

3. McDonnell PJ, Jacobs MR. Hospital admissions resulting from preventable adverse drug reactions. Ann Pharmacother. 2002;36: 1331-1336.

4. Senst BL, Achusim LE, Genest RP, et al. Practical approach to determining costs and frequency of adverse drug events in a health care network. Am J Health Syst Pharm. 2001;58:1126-1132.

5. Rodgers PT, Ruffin DM. Medication nonadherence: Part II - A pilot study in patients with congestive heart failure. Manag Care Interface. 1998;11:67-69.

6. McCarthy R. The price you pay for the drug not taken. Business Health 1998;16:27-33.

7. Brenner L. Taming the mail order beast. American Druggist. 1992;206 26-32.

8. Karve S, Cleves MA, Helm M, Hudson TJ, West DS, Martin BC. Good and poor adherence: optimal cut-point for adherence measures using administrative claims data. Curr Med Res Opin. 2009;25:2303-2310.

9. Schiff GD, Fung S, Speroff T, McNutt RA. Decompensated heart failure: symptoms, patterns of onset, and contributing factors. Am J Med. 2003;114:625-630.

10. Diette GB, Krishnan JA, Dominici F, et al. Asthma in older patients factors associated with hospitalisation. Arch Intern Med. 2002;162: $1123-1132$. 
11. Vaidya V, Holiday-Goodman M, Pinto S. Demographic disparities in patient-reported use of inhaled corticosteroids among patients with persistent asthma. J Asthma Allergy. 2010;3:101-106.

12. Vaidya V, Peeters MJ, Partha G, Potnis P. Evaluating the association between type of prescription drug plan and asthma patients' use of controller medications. J Pharm Health Serv Res. 2012;3:65-69.

13. Wu CH, Erickson SR, Piette JD, Balkrishnan R. The association of race, comorbid anxiety, and antidepressant adherence among Medicaid enrollees with major depressive disorder. Res Social Adm Pharm. 2012;8:193-205.

14. Wu J, Seiber E, Lacombe VA, Nahata MC, Balkrishnan R. Medical utilization and costs associated with statin adherence in Medicaid enrollees with type 2 diabetes. Ann Pharmacother. 2011;45:342-349.

15. Field KS, Briggs DJ. Socio-economic and locational determinants of accessibility and utilization of primary health-care. Health Soc Care Community. 2001;9:294-308.

16. Andersen RM. Revisiting the behavioral model and access to medical care: does it matter? J Health Soc Behav. 1995;36:1-10.

17. Andersen R, Newman JF. Societal and individual determinants of medical care utilization in the United States. Milbank Mem Fund $Q$ Health Soc. 1973;51:95-124.

18. Lieu TA, Lozano P, Finkelstein JA, et al. Racial/ethnic variation in asthma status and management practices among children in managed medicaid. Pediatrics. 2002;109:857-865.
19. Salas M, Hughes D, Zuluaga A, Vardeva K, Lebmeier M. Costs of medication nonadherence in patients with diabetes mellitus: a systematic review and critical analysis of the literature. Value Health. 2009; 12:915-922.

20. The NPCIE Coalition. Enhancing Prescription Medicine Adherence: A National Action Plan. Rockville, MD: National Council on Patient Information and Eduation; 2007. Available from: http:// www.talkaboutrx.org/documents/enhancing_prescription_medicine_ adherence.pdf. Accessed November 2, 2012.

21. Bateman ED, Hurd SS, Barnes PJ, et al. Global strategy for asthma management and prevention: GINA executive summary. Eur Respir J. 2008;31:143-178

22. Lane S, Molina J, Plusa T. An international observational prospective study to determine the cost of asthma exacerbations. Respir Med. 2006;100:434-450.

23. Yeaw J, Benner JS, Walt JG, Sian S, Smith DB. Comparing adherence and persistence across 6 chronic medication classes. J Manag Care Pharm. 2009;15:728-740.

24. Stanford R, McLaughlin T, Okamoto LJ. The cost of asthma in the emergency department and hospital. Am J Respir Crit Care Med. 1999;160:211-215.
Patient Preference and Adherence

\section{Publish your work in this journal}

Patient Preference and Adherence is an international, peer-reviewed, open access journal focusing on the growing importance of patient preference and adherence throughout the therapeutic continuum. Patient satisfaction, acceptability, quality of life, compliance, persistence and their role in developing new therapeutic modalities and compounds to

\section{Dovepress}

optimize clinical outcomes for existing disease states are major areas of interest. This journal has been accepted for indexing on PubMed Central. The manuscript management system is completely online and includes a very quick and fair peer-review system. Visit http://www.dovepress.com/ testimonials.php to read real quotes from published authors. 